\title{
MEDIA AND INCREASING PUBLIC TRUST IN MODERN IRAN: A CONCEPTUAL MODEL
}

\author{
Habib Ebrahimpour ${ }^{\mathrm{a}^{*}}$, Ali Khaleghkhah ${ }^{\mathrm{b}}$, Mohammad-Bagher Sepehri $^{\mathrm{c}}$ \\ a. Faculty of Humanities, University of Mohaghegh Ardabili, Ardabil, Iran \\ b. Faculty of Education and Psychology, University of Mohaghegh Ardabili, Ardabil, Iran \\ c. M.A in Media Management, Researcher and a teacher in the Ardabil News Faculty
}

\begin{abstract}
Public trust is one of the social capitals that can lead to integration in social systems. Trust links the citizens to organizations and institutions which are representing them and in this way it increases a government's legitimacy and effectiveness. In the communications industry nothing is more important than making the public trust the media. So building trust and reflecting the facts on social, political and economical issues is one of the essentials of media work. Hence, this study set out to investigate the effective factors which contribute to increasing public trust toward media and to give a conceptual model for it in Iran. In this sense, these questions were posed: what is public trust and what is media trust? What are the effective factors on each of these trusts? What appropriate models can there be for achieving public trust for a media in Iran? Finally, at the end some suggestions are given based on the 5 effective factors of public trust for media which can be manipulated to enhance media trust in modern Iran.
\end{abstract}

Keywords: Media, Public, Trust, Iran

\section{Introduction}

Public trust is one of the social capitals that creates and maintains integration in social systems and nurtures democratic values in a society. Trust links the citizens to organizations and institutions which are representing them and in this way it increases a government's legitimacy and effectiveness (Alvani \& Danaii-Fard, 2002). According to Alvani and DanaiiFard (2002, p. 9), public trust is "people's expectation of receiving positive responses to their requests from those in charge of public affairs". Just like the other organizations and

\footnotetext{
* Corresponding Author: ebrahimpourh@yahoo.com
} 
industries, media is also in need of public trust for effective broadcasting. By providing the groundwork for interacting with the people, media can become an effective tool for achieving some ends by the government.

In the past decade, different factors have resulted in the decrease of public trust toward governmental organizations: (1) the past decade saw some rapid changes in the societies which led to changes in people's needs and desires; (2) societies have become more diversified and this diversity requires diverse expectations (Jackson \& Bradford, 2009, p. 8); and (3) values, expectations and desires have changed in ways that people do not obey and believe authoritarian governments and their media as easy as the past.

In this sense, the society of modern Iran has not been segregated from the world social changes. From the 1990s, Iran has seen some vast demographic changes including the increase of public literacy, increase in number of women participating in social affairs, increase of job demands, emergence of new media, easier flow of information, more people becoming aware of their rights and the increasing influence of other societies. These changes have made the identification and provision of people's needs a struggle for the government. Thus, organizational governments such as IRIB, the biggest media organization of this country, and any other Farsi media are in need of identifying the new needs and demands of people of Iran in order to respond and coordinate with them. For this reason, this study set out to investigate the effective factors which contribute to increasing public trust toward media and to give a conceptual model for it in modern Iran.

To arrive at an answer, these main questions were posed: What is public trust and what is media trust? What are the effective factors on each of these trusts? What appropriate model can there be for achieving public trust for media in Iran?

\section{Public Trust}

'Trust' is not a new concept and has an old origin in the evolution of societies throughout history, which has now become a complex concept for itself. This idea has been incorporated into different social philosophies. Some of the discussions on the concept of trust were given by Silver (1985), Misztal (1996) and Seligman (1997).

In 1979, a thorough analysis was given on the concept of trust by Niklas Luhmann. According to him, trust is under the influence of complexity and uncertainty of modern societies which are accompanied by a lack of confidence and believability. In 1998, Bernard Barber had a review on the indicators of trust in different institution and work areas of modern societies and gave a typology on the types of expectations which are associated with trust (Abdolmaleki, 2008, p. 97). Trust has a rich theoretical background as one of the main bases of social and ethical philosophy. Up to now different definitions have been given for this concept, from which some have underwent major changes through time (Alvani \& Danaii-Fard, 2002, p. 7).

Trust is one of the components of social capital which has a close relationship with respect, confidence, satisfaction, believability, socialization, social solidarity and civil society. In this sense, trust is related to public policymaking and establishing social harmony. Although experts mostly pay attention to hard and materialistic tools in this matter, it is evident that available soft tools, cognitive structures and ethical tendencies among the people in a society are also important success factors for an institution or organization (Nasohian, 2008, p. 166). Eisenstadt and Roniger (1984) have concluded that trust is the most important element in interpersonal interaction which has been discussed from the ancient times up to now (Abdolmaleki, 2008, p. 97). 
Trust is a mental feeling, a feeling toward things around an individual or things unseen (Sapsford \& Abbott, 2006, p. 60). Also trust is defined as a psychological state which includes conditional acceptance of intention and purpose and is based on positive expectations of others' intentions and behaviors (Vlaar, Van den Bosch, \& Volberda, 2007, p. 409). Another definition defines trust as a mental state which lets people show their positive characteristics and achieve excellence with effort. Trust is convincing others (Chernyshenko, et al., 2009, p. 22). Trust means having confidence or believing in someone or something. Trust equals certainty, assuredness, and audacity (Brown \& Evans, 2009, p. 6). Trust is a psychological state related to an individual's capacity of confidence, plus his/her opinion of others' intentions and actions (Brown \& Evans, 2009, p. 1). Trust is a feeling which makes one confident in others based on the expectation s/he has of their skills and abilities (Chernyshenko, et al., 2009, p. 22). According to Malone and Malone (1987), trust is associating the real self with the other, knowing that one cannot be ridiculed, violated or assaulted and instead will be protected.

Bourdieu (1986) believes that public trust is considered as the people's personal experiences in encountering local powers. Trust signifies attitudes and actions which are driven from obvious evidences and documents. These evidences and documents include a feeling of sympathy and hostility which is the result of current level of confidence (Ashworth \& Skelcher, 2005, p. 20). Merriam-Webster Dictionary defines trust as reliance on the character, ability, strength, or truth of someone or something (Merriam-Webster Online Dictionary). The Oxford English Dictionary defines trust as (Bhattacharya, Devinney, \& Pillutla, 1998):

1. Confidence in or reliance on some quality or attribute of a person or thing, or the truth of a statement;

2. Accepting or giving credit to without investigation or evidence;

3. Giving credence to, believing (a statement); relying upon the veracity or evidence of (a person, etc.);

4. Confident expectations of something; and

5. The quality of being trustworthy, reliability, loyalty, trustiness.

Public trust is citizen's potential preparedness for cooperation and starting civil endeavor (Khezri, 2006, pp. 34-35). Whenever public trust is discussed, it means that people expect authorities and government officials to respond to their needs and desires interactively while there is an uncertainty and lack of understanding on how it is done. In other words, public trust means receiving positive responses from government on what people have demanded. That is why trust is present in different levels and fields of analysis regarding social disciplines (Alvani \& Danaii-Fard, 2002, p. 9). Offe (1999) believes that interactive and continuous communication between individuals leads to some kind of ethical and sensational commitment to their society which will result in increased social trust. Interaction and familiarity of individuals with each other results in understanding and awareness of others, supervising them and predicting their behaviors. These will result in mutual trust and confidence. So after trust is express to others, there are two ways to enhance that trust: (1) considering one's duty toward the other and (2) personal resources (Moidfar \& Jahangiri, 2009, pp. 54-55). 


\section{Types of Public Trust}

There are three approaches toward trust: (1) micro; (2) macro; and (3) integrated. The micro approach (or theories based on personal characteristics) considers trust as a personal feature or characteristic. In this way trust is related to an individual's behavior and features such as education, social class, income, age, sex, self-satisfaction, feeling success, etc. and his level of trust will be determined by them. The macro approach considers social trust as a feature of social system and not merely personal features. Based on this approach, only a small part of trust is determined by personal characteristics and people's level of trust depends on their evaluation of the amount of trustablity of their surrounding environment. People who live in a society in which the social system has high stability, social norms and social laws are obeyed, have a higher social trust. The integrated approach stated that each of the previously mentioned approaches (i.e. micro and macro) reveal different parts of the reality. Hence, some scholars have strived to define an integrated approach in order to arrive at a more complete picture of social trust (Abdolmaleki, 2008, p. 100).

From another point of view, Thomas (1998) questioned how public trust in government agencies could be maintained, restored, or even created. He suggested this to be a challenge because of the complexity surrounding trust and its many cognitive, emotional, and behavioral components. Overall, this author felt trust is based on what people believe rather than what people expect. So he classified trust into three different types which are mutual, social and fiduciary. However, different types of trust according to Offe (1999) are:

1. Citizens' trust to their fellow citizens or side category of other's world

2. Citizens' trust to political and non-political (e.g. the church, media, police, judiciary system or doctors) elite

3. Elites' trust toward each other in different fields such as commerce, labor, religious, academic, military, etc.

4. Trust of the upper levels of society to the lower levels. In other words, elites' trust to mass population's behavioral tendency.

Although most studies have been conducted on the second type of trust, Offe (1999) insists on horizontal trust among the non-elite (Moidfar \& Jahangiri, 2009, p. 52). Some of the other categorizations of trust are given in Table 1.

Table1. Different types of trust in different categorizations

\begin{tabular}{|c|c|c|c|c|c|}
\hline $\begin{array}{l}\text { Thomas } \\
\text { (1998) }\end{array}$ & $\begin{array}{l}\text { Giddens } \\
\text { (1990) }\end{array}$ & $\begin{array}{l}\text { Khezri } \\
(2005)\end{array}$ & $\begin{array}{l}\text { Offe } \\
(1999)\end{array}$ & $\begin{array}{l}\text { Adhami } \\
\text { (2007) }\end{array}$ & $\begin{array}{l}\text { Nazari and } \\
\text { Montzeri } \\
(2009)\end{array}$ \\
\hline $\begin{array}{l}\text { Mutual } \\
\text { Social } \\
\text { Fiduciary }\end{array}$ & $\begin{array}{l}\text { Fundamental } \\
\text { Interpersonal } \\
\text { Abstract } \\
\text { Generalized }\end{array}$ & $\begin{array}{l}\text { Public } \\
\text { Knowledge- } \\
\text { based } \\
\text { Special }\end{array}$ & $\begin{array}{l}\text { 1. Trust of citizens in their fellow } \\
\text { citizens } \\
\text { 2. The trust of mass constituencies } \\
\text { in political or other sectoral elites } \\
\text { 3. The horizontal trust extending } \\
\text { among political elites } \\
\text { 4. The top-down vertical } \\
\text { dimension of trust }\end{array}$ & $\begin{array}{l}\text { Experiential } \\
\text { Ethical }\end{array}$ & $\begin{array}{l}\text { Kinship } \\
\text { Social } \\
\text { Institutional } \\
\text { Religious }\end{array}$ \\
\hline
\end{tabular}




\section{Media}

Today's society is not imaginable without media. Mass media are very important for the society and depending on the type of system which a media follows, special people's needs and interests and the rate of development of that society differs. Mass media refers to a type of media which can send the same message to a large population simultaneously (Mohsenianrad \& Shafaghinejad, 2007, p. 23). Media itself is defined as instrument(s) by which the message is sent from the sender to the receiver, which includes journals, books, radio, television, satellite, internet and new media, etc. The common features of these types of media are anonymous receiver, fast transfer of information and vast distribution (Dadgaran, 2005 , p. 6). From an institutional point of view, media refers to any materialistic or nonmaterialistic tool, organization or institution which can bear a message, of course conditioning that the broadcasted message receives trust and acceptation among its audience (Farbod, 2007, p. 16).

\section{Types of Media}

Media are classified into 3 types based on form and content: (1) printed media such as press and journals; (2) electronic media such as radio and television; and (3) digital media such as CD, DVD, and Flash Memory (Hakimzadeh, 2007). In today's world, all of the following are considered as mass media and can affect a vast population: radio, television, journals, books, cinema, internet, weblog, radio weblog, podcast, cell phones, lectern, pulpit, minaret, photo, billboard, logo, graffiti, video game, etc. Each of these media has its own overt and covert functions which are determined based on each society's condition and environmental factors.

\section{Functions of media}

Harold Lasswell and Charles Wright are two of the scholars who have done extensive studies on the role and function of media in the society. They believe that media have functions such as supervision on the environment, creating social solidarity in response to environment, transferring cultural heritage and entertaining people (McQuail, 2003). These theoreticians believe that the first function of media is supervision, surveillance, and gathering and delivering information to the society about its peripheral environment. The second function of media is choosing and interpreting the gathered information. Media often includes criticizing and prescribing on people's behaviors and action toward events. In this role, the media promote social values, reveal the corruptions, serve as a reference for opinion leaders, prevent social instability and public fear, manage public opinion and supervise the government. Other functions of media are transfer of culture, promoting social solidarity and deepening common experience, decreasing social disorder and self-alienation, helping in people's socialization before and after formal education, and coherent community planning.

According to Harold Lasswell (1948), the leading American political scientist and communications theorist, media work as a transmission device of culture for transmitting information, values and norms from one generation to the next and from the society to the newcomers. In this way the media can enhance social solidarity by expanding the common experience. In addition, they help in connecting people to the society by maintaining people's socialization pre- and post school years. It is said that the media can decrease self-alienation and sense of separateness from the society by picturing a society which people can personify themselves within it (Severin \& Tankard, 2001, p. 452). In addition, the audience uses media for verifying their personal values, finding behavioral idols, imagery with others and achieving insight on who they are (McQuail, 2003). 
Beside what has been said about the functions of media by these scholars, it is evident that the media have much more functions in today's networked world. This is due to the fact that by the rapid development of media technology and emergence of an info-society worldwide, the role of media has become ever more important. Thus it is important for a media of this era to be competent and at same time serve its ends. The mission of each type of media is different from the other in that if a media functions to give services for a particular society, for instance, its services will be highly dependent on that particular society's features and needs. In other words, the functions of each media are defined by the ends they are supposed to achieve.

In a book entitled "Social Organization: a Study of the Larger Mind", Charles Horton Cooley argues that if we cannot truly understand the effect of communication revolution on the world, we shall gain no understanding of the modern world. According to him, communications is a mechanism which organizes the society and facilitates public relations. This modern world of communication will lead to fundamental changes in the way people think. In other words, communications will expand a minds insight and will force the thought toward mobility by innovation. This condition is the result of using modern communications and will enhance based on the four roles which are: (1) Expression or variety of thoughts and senses which are expressed to others; (2) Continuity of memory or victory over time; (3) Velocity or victory over space; and (4) Being accessible to all human kind (Motamednejad, 1992, p. 45).

Truthfully, the role of media in the modern world is so important that we cannot imagine our world without them. Media are not merely for popular entertainment and have a vast role in many of our social and personal activities. It is not far from truth if we call the modern people as 'the media people' and the modern culture as the result of 'media culture'. The modern human beings are exposed to media from birth to death. They think with the aid of media, they see the world from the media's viewing glass, and try to adopt their behavior and values to what they understand from them. In addition, the media (books, internet, movies, etc.) are deciding which school(s) of thought should be dominant among the majority. Some of the recent socio-psychological studies on mass media reveal that mass media have such a power that they can bring about a new generation in the history of mankind which is incomparable to the previous generations in stance of culture, values, ideals, and norms (Saroukhani, 2010, p. 94).

\section{The role of media in establishing public trust}

Today by the transmission of new information, knowledge and exchange of ideas, the mass media such as press, radio, television, etc. are having an undeniable role in the progress of man's culture and civilization in such a way that this era is called the "age of communication". Abundance of population, centralization of big masses in large cities around the globe, the condition of the industries, complexity of social life, national and international interdependency, insecurity and crises, rapid changes in the political and social systems (especially in the Middle East and North Africa), transformation of cultural bases, putting aside many of the traditional values and beliefs and awakening of social conscience are some of the reasons which make people desire to know more and be aware of what is happening in their world. In other words, the mass media have become an inseparable part of consolidating democratic values and international understanding.

In such societies people will try to be aware of all the changes and events of their world so that they can make the right decisions and changes to their lives and play their own role 
directly and indirectly when the time comes. That is why social awareness is considered as one of the most important features of contemporary world and it is this awareness that makes people become interested to their social and personal lives with all its liberties and responsibilities. Consequently, one can only achieve the best of social and personal life with confidence if s/he has the required knowledge of what is going on in the world and this can only be attained by the help of media.

Gaining information and sending it to the target groups, constructing communications, converging and achieving public opinion, and making people understand and follow the national and international policies in this complex world is an exhausting task for any media. That is why, considering the following factors are essential for any media to be successful in any society:

a) Gaining public trust: This factor is one of the most important roles of media, especially regarding national policies of the governments and international policymaking. In this stance, media can picture the aims, objectives, and priorities of national and international social and cultural programs so that there is little unrest against new changes and developments.

b) Reflecting the truth: Demonstrating the truth of what is going on in the world, economically and socially, is also an essential part of media's role. The very important rule is that a media should not take sides directly and overtly and broadcast different point of views.

c) Constructive criticism: Having a realistic view toward social, political and economical affairs is a constructive criticism for itself. Aside picturing the reality with the least interference, making comments with honest impartial judgments is the next step for constructive criticism.

d) Predicting crises: A media can be more successful than its competitors when it correctly predicts the coming crises. Analyzing, predicting, and overcoming the crises which a media can face is another essential role of successful media.

e) Credibility: All media have to follow some required rules, such as reporting news which are exact, valid, popular, and newsworthy, in order to achieve credibility. Following these rules, which might have different definitions in different contexts and cultures, are an important part of media work.

f) Publicity or propaganda: Publicity or propaganda is one of the key elements for a media's survival. This is an educational activity which is undertaken to spread knowledge, increase political, social and cultural awareness, and publicize ethical values and norms. In addition, educating, deepening the awareness in the recipient society and achieving public opinion are also very important.

g) Opinion polls: One of the important tools for evaluating people's responses to different issues and programs is conducting opinion poll by surveys, interviews, comments, etc. In this way a media can improve and adapt its work to the public desire and give feedback to the government for national programs.

All and all, achieving public opinion is one of the key struggles of media. Having no trust toward a media for reasons such as rent breaking, not having reliable references, not having specialty in the genre, subject or target audience, and ignorance toward people's desires is common in many countries worldwide. However, this distrust seems to be more obvious in developing countries due long histories of dictatorship and social suppression. Inappropriate news work (e.g. not considering the target society) and delivering obviously wrong 
information to audience, especially in the developing countries, can lead to a heavy mistrust toward the media, even if they are world-famous such as BBC, VOA, Euronews, Russia Today, Al Jazeera, etc.

In other words, in order to be successful in the developing countries, a media should address the very sensitive areas of that developing country's society. A media should make people think about the current issues of their society, introduce new ideas in different social and cultural aspects, make people's voice be heard and let them criticize their own society, help to increase the knowledge of the target people and respond to their need to know, conduct talk shows and discuss the important issues for the public, picture the reality with no disruption and interference, etc., and in doing so, it can achieve a large audience and become the new effective way of changing people's lives in the developing world.

\section{Public trust and media}

Building trust is crucial for a media's success. If there is no trust toward a media, that media will have no audience. A media without audience is very much ineffective, no matter what professional technique it uses for persuasion. In case of news networks, gaining public trust is like a hidden treasure which is sought in different ways by all media corporations and organization. In other words, if the people do not trust a news agency, that media will be scattering information to an empty space where there are no recipients and no effects.

Among the prophecies of mass media, gathering and broadcasting information and news is one of the most basic objectives. Basically mass media are born with news. Broadcasting news and information shapes the character of a media corporation or organization. Today with the advent of new technologies and fast transmission of information to all around the world, new information and news are no longer kept from the public. That is why the genre of news is in need of public trust more than the other genres of media and television. In much the same way that the news spreads fast and effects people, people's reaction is also fast and this boomerang of media corporations and organizations receives the reaction and feedback in a little time.

Hence, the news is the basic programming for achieving or losing media trust for a media organization. The amount of trust toward the news broadcast of a media to large extent determines the amount of public trust toward that media itself. The phenomenon of trust exists in the simplest forms of social capital and analyzing this trust and determining its amount is very complex. Today media have to struggle with the challenges of achieving public trust in every news programming and have to try to increase it so that they can reward the audience with what Wilbur Lang Schramm (1964) calls it immediate reward.

Two patterns can be defined in the field of communications: (1) Linear and (2) Nonlinear. The linear pattern includes message, recipient, sender, method of sending and the interactive method of receiving feedback. The non-linear pattern is the desirable pattern for media in which a media has a positive interaction with the audience and the audience accepts what they receive from that media. For this to happen, trust must exist between the media and audience. Trust and distrust are the two edges of one knife. In case of news, trust exists when the people accept what they hear from the media leading to some social, economical or political effect in the society and distrust is when no one cares about what the news is saying. In this way, all the professional techniques and tricks used in news programming will not help to undertake the required effects in the society. 


\section{Indicators of media trust}

According to the researcher's knowledge, 16 indicators have been mentioned regarding media trust in the works of media proponents. Among these indicators, the quality and software indicators have had a special place. In this regard, the effective factors on trusting a media are categorized into 5 categorize which are:

1. Message Factors: These factors are about quality and content of sent messages and they insist on taking into account the amount of audience knowledge and understanding. The indicators of these factors are: being purposeful, being attractive, being realistic and credible, being scientific and research-based, being based on audience needs, and having fast transmission.

2. Audience Factors: These factors state that the audience will not accept whatever they receive via media transmission. The audience can decide on what to believe and media are not the only determining factors. The indicators of these factors are: being based on audience needs, having the right to choose, audience satisfaction, being effective in solving problems, addressing current social issues, continuous interaction with audience, and receiving feedbacks.

3. Contextual Factors: These factors are characteristics of the ecology/environment that are related to the effectiveness of a media. The indicators of these factors are: political sociability and ethnic, national and cultural characteristics.

4. Attitudinal Factors: Trusting or distrusting the news resources will affect the quality and amount of influence which the news will have on audience attitude. The indicators of these factors are: favoring news, media objectivity, distancing from party and special groups interests, avoiding negativism, avoiding cliché, avoiding exaggeration, avoiding distortion and giving contradictory information.

5. Functional Factors: These factors are related to the duties and functions of media and some of their indicators are: program efficiency and effectiveness, program penetration ratio, number of audience, program diversity, program comprehensiveness, covering the assumed functions of media in production and broadcasting.

Not all of these indicators are present in all of the produced programs of a media. The social feedback and effect of using these indicators too much or even too little will be revealed in long time, while the managers and directors of different sections of a media will be encountering the primary reaction of people in a short time. For instance, news is about answering the emergent, unpredictable and consecutive need of people to know and this makes people's reaction and sensitivity toward it increasingly high. Now based on the above mentioned factors which determine the amount of public trust toward a media, a conceptual model was given for increasing public trust in Iran (Figure 1).

\section{Discussion}

Social trust is one of the key fundamentals of social capital in any society. Trust nurtures the democratic values in the different levels of the community and legitimizes the organizations and institutions which are rooted in the government. Trust is mostly a mental issue which acts in different approaches and cannot be established within a society without its requirements.

Maybe one of the most important requirements for establishing trust between the people and a government is media. Due to their vast and diverse effect, the media have become a 
lever for increasing or decreasing trust in societies. In this sense, the media have to use all the possible approaches and factors in order to obtain public trust for their organization or government.

The question that still remains is that whether any kind of trust in any scale or amount would be acceptable for a media or not? The answer is that an average level of trust can be the utmost useful and productive. Why? Because if there is too much trust based on emotions and indulgence, most probably the trust cannot stand the test of time and root into the deeper layers of the society. So the media are recommended to be in the middle line of the path of gaining public trust, especially in unpredictable countries such as Iran, and do not seek to gain much trust in a short time for their government, organization or institution, even if it is possible in some conditions.

Many believe that the media can be very influential in changing people's believes and desires. However, this influence can be achieved only if the people trust the media. Now if a media is trusted by the people, this same media can become the leverage of a government for doing whatever it wants and thus lead to loss of democracy in that society. This is because day by day the government will try to make the people think and act the way it wants by the help of this trusted media, thus becoming less tolerant toward criticisms of its values and acts and will try to cover up its pitfalls and deficiencies by any means possible by the help of that trusted media.

Such a misused media will not retain the public trust for long and sooner or later the people will try to find other means or media for achieving what they desire, which is trustable information and reliable news. In this way, the misused media which was once trusted by the people will not only lose public trust, it will also have more problems in regaining this trust in respect to a media which has just begun its work.

Today, due to the abundance of accessible media all around the globe, people can more easily notice the misuses of their trust by a media, especially in many middle-eastern countries which have experienced long-term media suffocation. The competition of different media in this region is the reason which has made them to do whatever they can to achieve more audience or in other words, increase their public trust. In Iran, the recent decade has seen the rapid increase of media literacy among the Farsi-speakers. Although according to Reuven Frank, a former president of NBC News, it is unlikely that general viewers become so sophisticated with the techniques that they could discount them all (Jones, 1985), day by day more people in this country are becoming aware of some of the techniques by which the media use to change their believes and thoughts.

There are no objective neutral media. Every media, especially in case of news, will seek to satisfy the demands of a political group, party or government. In this situation, the media can obtain public trust for their news network by setting the words and discourse in a way that it seems more neutral to the viewer. Still the viewers are the ones who will choose what to believe while the media are trying to make them believe whatever they say.

Retrieving the lost public trust for a media is a great struggle, especially in Iran. So it would be more sensible to do whatever that is necessary to retain whatever amount of trust which has been achieved. Distorting the reality for the sake of power and money cannot last long in the era that people can find out the truth much faster than before by many different means. It is better to put the reality into your own words and ideological discourse, than to change it into something so different that it can be easily denied by the people. 


\section{Conclusion}

Due to the intermediate interactive role of media between the government and the people, this article set out to investigate the effective factors which make this interaction constructive. After defining public trust and media trust, a conceptual model was given. Now based on this model, the following suggestions are given to those media who seek to achieve public trust in modern Iran:

Increasing public trust for a media in Iran is dependent on including the required indicators of media trust in decision-making, production and broadcasting of programs. From among the various indicators, being purposeful, being attractive, being realistic and credible, being scientific and research-based, being based on audience needs, and having fast transmission are more important in this country.

Considering audience factors comes next. The audience in Iran will not accept whatever they receive via media transmission, especially based on their contemporary historical experiences, even if it is from a very reliable and credible resource. Due to what has been going on in this country in the last century, people have become very much suspicious toward any news they receive from any media. So the media which seek the trust of Iran's society should act a little different than what they do to achieve public trust in western or even other eastern countries.

Since the news are the forefront of achieving public trust for any media corporation or organization, especially in Iran based on its deep social structures, paying attention to favoring news, media objectivity, distancing from party and special groups' interests, avoiding negativism, avoiding cliché, avoiding exaggeration, and avoiding distortion and contradictory information can help a lot in achieving the people's trust.

The functional factors have a direct effect on achieving the mission of a media. Manipulating all the required indicators, such as program efficiency and effectiveness, program penetration ratio, number of audience, program diversity, program comprehensiveness, and covering the assumed functions of media in production and broadcasting, will be essential in achieving public trust in Iran.

Last but not least, considering the ethnic, national, cultural and historical characteristics of this nation and including its special political factors will also be essential in achieving public trust in Iran. In this regard, a very important note is that the people of Iran care very much for some of their historical heritage, e.g. the name of Persian Gulf. Ignoring or confronting the people in this regard can lead to very big mistrust issues for any media which cares to achieve public trust in Iran.

\section{References}

Abdolmaleki, A. (2008). Assesing Social Trust, Its Effective Factors and the Role of Media in Increasing It. Pajouheshaye Ertebati (Communications Research), 15 (53), 128-195.

Alvani,S. M., \& Danaii-Fard, H. (2002). Modiriyate Dolati va Etemade Omumi (Public Administration and Public Trust). Danesh Modiriyat (Knowledge of Management), 14 (15), 5-27.

Ashworth, R., \& Skelcher, C.(2005). Meta-Evaluation of the Local Government Modernization Agenda: Progress Report on Public Confidence in Local Government. West Yorkshire: ODPM Publications.

Barber, B. (1998). Intellectual Pursuits: Towards an Understanding of Culture. Lanham: Rowman \& Littlefield Publishers.

Bhattacharya, R., Devinney, T. M., \& Pillutla, M. M.(1998). A Formal Model of Trust Based on Outcomes. The Academy of Management Review, 23 (3), 459 - 472.

Bourdieu, P. (1986). The Forms of Capital. In J. G. Richardson (Ed.), Handbook of Theory and Research for the Sociology of Education (pp. 241-258). New York: Greenwood Press. 
Brown,R., \& Evans, E. (2009). Public Confidence in the Police: A Review of Research. Lincoln: Assciation of Police Authorities.

Chernyshenko, D., Davies, S., Deighton, P., Fleurot, O., Frost, D., Gent, C., et al. (2009). Seven type of confidence. The Company Agency.

Dadgaran, S. M. (2005). Mabani Ertebatat Jami (Mass Communications: The Basics). Tehran: Morvarid va Firouzeh Publications.

Eisenstadt, S. N., \& Roniger, L.(1984). Patrons, clients and friends: interpersonal relations and the structure of trust in society. Cambridge: Cambridge University Press.

Farbod, M. S. (2007). Konesh Moteghabel Farhang va Resaneh (Mutual Interaction of Culture and Media). Farhange Resaneh (Media Culture) , 1 (1), 16-19.

Giddens, A. (1990). The Consequences of Modernity. London: Polity Press in association with Blackwell.

Hakimzadeh, H. (2007, July 28). Anvaye Resaneha (Types of Media). Retrieved January 15, 2012, from Mashghe Journalism (Journalism Drill): http://raveshtahqiq.blogfa.com/post-16.aspx

Jackson, J., \& Bradford, B.(2009). Crime, policing and social order: on the expressive nature of public confidence in policing. British Journal of Sociology, 60 (3), 493-521.

Jones, A. (1985, February 17). New York Times, p. 8E.

Khezri, M. (2006). Government and Social Capital. Motaleate Rahbordi (Strategic Studies) , 9 (31), 31-52.

Lasswell, H. (1948). The Structure and Function of Communication in Society. In L. Bryson (Ed.), The Communication of Ideas (pp. 37-51). New York: Institute for Religious and Social Studies.

Luhmann, N. (1979). Trust and Power: Two works by Niklas Luhmann. Brisbane: John Wiley.

Malone, T. P., \& Malone,P. T. (1987). The Art of Intimacy. New York: Prentice Hall.

McQuail, D. (2003). Mass Communication Theory An Introduction (3rd ed.). (P. Ejlaly, Trans.) Tehran: Center for Media Research and Studies Publications.

Merriam-Webster Online Dictionary.(n.d.). Trust-Definition. Retrieved January 15, 2012, from Merriam-Webster Online Dictionary: http://www.merriam-webster.com/dictionary/trust

Misztal, B. A. (1996). Trust in Modern Societies. Cambridge, UK: Polity Press.

Mohsenianrad, M., \& Shafaghinejad, N.(2007). Ertebat Shenasi: Ertebatat Ensani (Knowing Communication: Human Communication). Tehran: Soroush Publication.

Moidfar, S., \& Jahangiri, P.(2009). Generalized Social Confidence and its Influential Social Factors: The Case of Urmia. Daneshnameh Olumeh Ejtemaii (Journal of Social Sciences) , 1 (1), 47-67.

Motamednejad, K. (1992). Vasayele Ertebate Jamii (Mass Communication Devices). Tehran: Allameh Tabatabii University Press.

Nasohian, M. M. (2008). The Role of Mutual Trust Between the Goverment and the People in Political Development. Rahbord Yaas (Yaas Strategy) (14), 165-180.

Offe, C. (1999). Trust and Knowledge, Rules and Decisions: Exploring a Difficult Conceptual Terrain. In M. E. Warren (Ed.) Democracy and Trust. Cambridge: Cambridge University Press.

Sapsford, R., \& Abbott, P.(2006). Trust, confidence and social environment in post-communist societies. Communist and Post-Communist Studies, 39 (1), 59-71.

Saroukhani, B. (2010). Jamesheni Ertebatat (Sociology of Communications). Tehran: Ettela'at Press.

Schramm, W. L. (1964). Mass Media and National Development: The Role of Information in the Developing Countries. Stanford: Stanford University Press.

Seligman, A. B. (1997). The Problem of Trust. Princeton: Princeton University Press.

Severin, W. J., \& Tankard, J. W.(2001). Communication Theories: Origins, Methods and Uses in the Mass Media (5th ed.). (A. Dehghan, Trans.) Tehran: Tehran University Press.

Silver, A.(1985). Friendship and Trust as Moral Ideals: a Historical Approach. American Sociological Association meeting (p.Unpublished paper). Washington DC: 26-30 August.

Thomas, C. W. (1998). Maintaining and Restoring Public Trust in Government Agencies and their Employees. Administration and Society, 30 (2), 166-194.

Vlaar,P. W., Van den Bosch, F. A., \& Volberda, H. W. (2007). On the Evolution of Trust, Distrust, and Formal Coordination and Control in Interorganizational Relationships: toward an Integrative Framework. Group \& Organization Management, 32 (4), 407-428. 